\title{
batillot
}

\section{O advento do Constitucionalismo na China}

\author{
Egas Moniz Bandeira ${ }^{1}$ (Universidade de Heidelberg, Alemanha) \\ egas.moniz-bandeira@asia-europe.uni-heidelberg.de
}

Karl Jaspers Centre for Advanced Transcultural Studies

Voßstraße 2, Building 4400 Room 007

69115 Heidelberg, Germany

\footnotetext{
1. Doutorando em Estudos Chineses (Sinologia) na Universidade de Heidelberg (Alemanha) e em Direito/ História Política na Universidade Tohoku (Sendai/Japão). Graduado em Direito pela Universidade de Heidelberg (Alemanha). Advogado.
} 


\title{
Resumo
}

No século XIX e no início do século XX, o constitucionalismo era uma tendência mundial, não só na Europa e nas Américas, como também na Ásia: $O$ Japão outorgou uma constituição em 1889/90, a Coréia, em 1899, e a Pérsia, em 1906. O governo chinês anunciou a sua intenção de outorgar uma constituição em 1906, mas a dinastia imperial foi forçada a abdicar em 1912 sem haver promulgado uma carta constitucional definitiva.

O presente artigo apresenta essa primeira tentativa de introdução do constitucionalismo na China como reação a fatores internos e externos. Ao mesmo tempo que a constituição era uma nova forma de legitimar-se internamente, ela trazia vantagens no cenário internacional. A experiência chinesa mostra que, mesmo que superficial, ter uma forma constitucional de governo estava a tornar-se um dos elementos definidores do Estado na ordem mundial emergente.

Palavras-chaveः China, constituição, monarquia, absolutismo, globalização do direito

\section{The advent of constitutionalism in China}

\begin{abstract}
In the $19^{\text {th }}$ and the beginning of the $20^{\text {th }}$ century, the adoption of constitutionalism was a world-wide tendency, not only in Europe and in the Americas, but also in Asia: Constitutional texts were promulgated in Japan in 1889/1890, in Korea in 1899 and in Persia in 1906. The Chinese government announced its decision to implement a constitutional mode of government in 1906, but the ruling dynasty was forced to abdicate in 1912 without having promulgated a full and definitive constitutional charter.

The present article presents this first attempt to introduce constitutionalism in China as a reaction to internal as well as external factors. At the same time that the constitution was a novel form of internal legitimation, it also had advantages in the international arena. The Chinese experience shows that, even if only superficial, having a constitutional form of government was becoming one of the defining elements of states in the emerging world order.
\end{abstract}

Keywords: China, constitution, monarchy, absolutism, globalization of law 


\section{Introdução}

Conquanto no final do século XIX a maior parte dos países ocidentais tivesse constituições escritas, a sua função muitas vezes não era levada a sério. Assim, Otto Mayer (18461924), uma das maiores autoridades do direito administrativo alemão, ainda ensinava que «o direito constitucional passa, mas o direito administrativo fica» (Verfassungsrecht vergeht, Verwaltungsrecht besteht ${ }^{93}$ ). Mesmo assim, a noção de que um estado soberano precisa de uma carta constitucional tornou-se quase universal. Hoje, quase todos os países em todos os continentes possuem constituições codificadas. Ironicamente, uma das poucas exceções é um dos berços do constitucionalismo: o Reino Unido.

Portanto, como, quando e porquê essa idéia tornou-se universal? O século XIX foi um tempo de grandes mudanças políticas, econômicas e sociais no mundo inteiro, bem como de crises de identidade decorrentes da necessidade de adaptar-se às novas circunstâncias. As grandes crises políticas e sociais, tanto no Ocidente como no Oriente, foram acompanhadas por novas cartas constitucionais. Assim, em uma tentativa de modernização, o Império Otomano pôs em vigor a sua primeira constituição em 1876. No Japão, o Imperador Meiji ( $r$. 1867-1912), logo após a sua ascenção ao trono, iniciou um programa de profundas reformas políticas, cujo cerne foi a outorgação de uma constitutição no ano 1890. Poucos anos depois, quando o Rei Kojong da Coréia se declarou Imperador (sob o nome de Kwangmu), um dos seus primeiros projetos foi a outorgação de uma constituição, no ano 1899.

Em 1904, eclodiu a guerra russo-japonesa, na qual o Império Russo sofreu uma grave derrota contra o Japão, país muito menor tanto em termos de área quanto de população. A vitória japonesa, portanto, foi vista como a vitória do constitucionalismo sobre o absolutismo não-constitucionalista, e teve fortes influências diretas e indiretas: A Rússia, que passava por uma forte crise interna, outorgou uma constituição em 1905/1906. Indiretamente, a vitória japonesa influenciou a «revolução constitucional» na Pérsia, onde uma constituição foi estabelecida em 1906. Também influenciou fortemente os pensadores chineses e o governo de Pequim, que, no mesmo ano de 1906, anunciou a sua decisão de outorgar uma constituição.

Partindo do exemplo da Ásia Oriental, e especialmente da China, o presente artigo argumenta que o constitucionalismo tornou-se um elemento importante do state-building na época. Sob esse pano de fundo, a tentativa de reforma constitucionalista do governo chinês deve ser reavaliada: As reformas projetadas pelo governo respondiam a fatores internos bem como a fatores externos.

No plano interno, a China tinha uma tradição milenar de organização governamental e administrativa. Porém, diante dos imensos desafios da época, o governo chinês necessitava de uma nova legitimação para si, objetivo que poderia ser alcançado mediante a outorgação de uma constituição. Por outro lado, no plano externo, as constituições estavam a tornar-se um dos elementos definidores do Estado na ordem mundial emergente, e o fato de ter uma constituição trazia vantagens no cenário internacional. A corte de Pequim tinha consciência disso e de que o constituicionalismo era uma tendência mundial da época.

93. Mayer 1924, p. 9. 


\section{O constitucionalismo e a ordem mundial: o exemplo japonês}

As reformas constitucionais chinesas não podem ser compreendidas sem as reformas constitucionais japonesas, que serviram de modelo para o governo chinês. Em meados do século XIX, desmoronou o sistema político do Xogunato de Tokugawa, marcando o fim do período Edo. Em 1853/1854, Matthew Calbraith Perry (1794-1858), Comodoro da Marinha dos EUA, forçou a abertura dos portos japoneses para o comércio exterior. Na seguida, o Japão teve de assinar uma série de tratados com cláusulas bastante desvantajosas, caracterizados pela historiografia como «tratados desiguais».

Em 1867, ascendeu ao trono o imperador Meiji, que logo em 1868 iniciou um extenso programa de reformas políticas. Em 1871, o governo Meiji enviou a Missão Iwakura aos Estados Unidos e à Europa para renegociar os tratados desiguais e ao mesmo tempo estudar as sociedades ocidentais com o objetivo de modernizar o Japão. Embora a missão não tenha conseguido renegociar os tratados, o Japão continuou os seus esforços de modernização e nas próximas décadas tornou-se uma maior potência militar e industrial.

Os esforços de modernização do Japão extenderam-se também ao domínio jurídico e constitucional ${ }^{94}$. O governo do Japão anunciou o objetivo de gradualmente avançar em direção ao constitucionalismo e apresentou uma primeira minuta de constituição em 1878 . Em 1881, o Imperador anunciou a abertura da Assembléia Nacional em 1890. Em 1882/1883, uma missão chefiada por Itou Hirobumi visitou vários países da Europa e os Estados Unidos especificamente para estudar as respectivas constituiçóes. Em 1884, foi criada por ordem imperial a Autoridade para a Pesquisa de Sistemas Políticos (Seido torishirabe kyoku).

A Constituição do Império do Japão foi proclamada a 11 de fevereiro de 1889 e entrou em vigor em 1890, seguindo essencialmente o modelo alemão (prussiano). ${ }^{95}$ Essa constituição revelou-se muito estável e permaneceu em vigor até o final da Segunda Guerra Mundial, mesmo que a verdadeira forma de governo haja mudado bastante durante essas cinco décadas. ${ }^{96}$ Depois de finalizada a reforma política e proclamada a constituição, o Japão logrou a renegociar os tratados desiguais da década de 1850, e por sua vez tornou-se uma potência imperialista na Ásia Oriental, tratada como igual pelas potências ocidentais.

\section{A tentativa chinesa de reforma constitucional, 1905-1908}

A idéia do constitucionalismo começou a ter um forte impacto na China na década de 1890. Nas últimas décadas do século XIX, em meio de crises internas e externas, intelectuais chineses procuravam vias de fortalecer a China, de modo que ela pudesse superar o seu atraso em relação às potências da época. Uma vez que o movimento de auto-fortalecimento, iniciado

\footnotetext{
94. Sobre o processo constituinte no Japão ver 大石眞 Oishi Makoto 1996, pp. 15-228.

95. Texto da constituição reproduzido em 明治前期の憲法構想 Meiji zenki no kenpô kôsô 1967, pp. $335-340$

96. Röhl 2005, p. 51.
} 
na década de 1860 e focado na modernização militar e industrial do país, não surtira os resultados desejados, pela virada do século a interpretação mais comum era de que o segredo do sucesso não estava só na modernização tecnológica, mas especialmente na organização e nas instituições do Estado.

O que era necessário para a China seria, segundo pensadores como Kang Youwei, Liang Qichao e Huang Zunxian, o estabelecimento de um regime constitucional. Ao mesmo tempo, o pensamento de Charles Darwin gerou, entre os pensadores chineses da época, a idéia de que a mudança de sístemas políticos, resultando em governos constitucionais, seria um processo evolucionário. ${ }^{97}$

A Imperatriz Viúva Cixi, que era tida como reacionária desde que suprimira a reforma dos 100 dias em 1898, anunciou reformas políticas em 1901. A vitória japonesa na guerra russo-japonesa em 1905 foi o fator decisivo para que o governo chinês decidisse introduzir um modo de governo constitucional. Ainda em 1905, imitando as missóes japonesas, a corte imperial de Pequim mandou delegações ao exterior para estudar as leis e instituições do Japão, dos países europeus e dos Estados Unidos.

A 25 de Novembro de 1905, a Imperatriz Viúva Cixi ordenou que o Conselho de Estado (Zhengwuchu) estabelecesse um Órgão para Investigação da Politica (Kaocha Zhengzhi Guan), cuja tarefa seria não só colecionar as leis dos diversos países, mas também de deliberar sobre as suas respectivas vantagens e desvantagens, bem como reunir as conclusóes em forma escrita. ${ }^{98}$

No verão de 1906, depois de a missão ao exterior retornar de sua viagem de estudos, seus participantes vigorosamente pronunciaram-se a favor do estabelecimento de um regime constitucional..$^{99}$ A 26 de Agosto de 1906, a Corte de Pequim estabeleceu uma comissão para avaliar os relatórios escritos pelos comissários constitucionais. ${ }^{100}$ A nova comissão foi composta pelas figuras mais importantes na Corte, ou seja, por Zaifeng (Príncipe Chun, Imperador-Regente da China entre 1908 e 1911), pelos ministros do Conselho Imperial (Junjichu), pelos ministros do Conselho de Estado (Zhengwuchu), pelos ministros do Secretariado Imperial (Neige) bem como por Yuan Shikai, vice-rei da província de Zhili e um dos mais poderosos políticos da época. ${ }^{101}$

Os membros da comissão reuniram-se com a Imperatriz Viúva Cixi a 29 de Agosto de $1906{ }^{102}$ É dito que durante aquela reunião, os participantes decidiram de outorgar uma constituição e instituir uma representação parlamentar a partir do ano 35 do Imperador Guangxu (1910), ou seja, após três anos. ${ }^{103}$

\footnotetext{
97. Uma curta discussão das diferentes posições chinesas sobre o contitucionalismo e a teoria evolucionária encontra-se em Pusey 1983, pp. 337-338.
98. 故宮博物院明淸檔案部 Gugong Bowuyuan Mingqing Dang'an Bu 1979, p. 43 (Guangxu 31/10/20).
99. Cf. p. ex. a petição ao Trono de 25/08/1906: 故宮博物院明淸檔案部 Gugong Bowuyuan Mingqing
Dang'an Bu 1979, pp. 367 e segs. (Guangxu 32/07/06).

100. United States Department of State 1909, pp. 348-349.

101. United States Department of State 1909, pp. 348-349.

102. Notes on Native Affairs. The Question of a Constitution, in: The North China Herald, 8/31/1906 (2038), p. 544.

103. Notes on Native Affairs. The Question of "Time.", in: The North-China Herald, 9/7/1906 (2039), p. 571. 
Dois dias depois, a $1^{\circ}$ de setembro de 1906, o governo anunciou a sua intenção de outorgar uma constituição dentro de poucos anos, depois de um processo de preparação constitucional. ${ }^{104} \mathrm{O}$ decreto formalizando a decisão de adotar um governo constitucional para a China previa uma reforma completa do estado chinês em vários passos: a primeira reforma trataria do serviço público, a ser seguida pela elaboração das mais diversas leis para o império ${ }^{105}$. Depois disso, reformas deveriam modernizar o sistema educacional, as finanças bem como as forças armadas e a polícia. $\mathrm{O}$ objetivo de todas essas reformas era preparar os fundamentos do constitucionalismo. $\mathrm{O}$ decreto de $1^{\circ}$ de setembro era uma declaração de princípio, mas ainda não especificava detalhes da constituição vindoura.

Ao contrário da decisão supostamente tomada no dia 29 de agosto de 1906, o decreto de $1^{\circ}$ de setembro não previa datas concretas nem para as reformas nem para a outorgação da constituição. Só constatava que a preparação constitucional deveria ser terminada após «alguns anos», quando a Corte decidiria uma data para outorgar a constituição. Observadores contemporâneos explicaram essa falta de clareza como sendo resultado das maquinações de Tieliang, àquela época ministro da guerra e tido como líder do partido de oposição às reformas constitucionais. ${ }^{106}$ Ele teria pedido Cixi de mudar a palavra «três» da minuta original para a palavra «alguns» ${ }^{107}$ Por causa da falta de uma data concreta, o decreto foi recebido como insatisfatório e decepcionante. ${ }^{108}$

Por outro lado, as reformas mencionadas no decreto mostram que a carta constitucional deveria ser acompanhada por profundas reformas políticas. O documento constitucional seria a coroação de um extenso e ambicioso projeto de reestruturação nacional. Portanto, como assinalava um telegrama da Legação dos Estado Unidos em Pequim, até mesmo «alguns anos» poderiam ter sido curtos demais para efetuar tal «enorme» programa. ${ }^{109}$

Um segundo decreto ${ }^{110}$, promulgado apenas um dia depois, a 2 de setembro de 1906, designou dois comissões de trabalho. Quase todos os membros da comissão de avaliação de 26 de agosto de 1906 também delas participaram, exceto o príncipe Zaifeng, Wang Wenshao e Lu Chuanlin. Os dois últimos, que eram supostamente opostos a reformas, haviam-se recusado a participar de uma comissão cuja tarefa seria promover reformas. ${ }^{11}$

104. 故宮博物院明淸檔案部 Gugong Bowuyuan Mingqing Dang'an Bu 1979, pp. 43 -44 (Guangxu $32 / 7 / 13)$.

105. Diplomatas britânicos na época interpretaram o decreto imperial como falando da «revisão das leis dinásticas do Império» sendo o segundo passo das reformas, Nish 1993, p. 17. Porém, o decreto não fala das leis de sucessão dinástica, mas usa a expressão stodas as leis". O segundo passo da reforma, portanto, seria a compilação de modernos códigos legais (civil, criminal etc.).

106. Notes on Native Affairs. The Question of "Time., in: The Nortb-China Herald, 9/7/1906 (2039), p. 571.

107. Notes on Native Affairs. The Question of "Time.", in: The North-China Herald, 9/7/1906 (2039), p. 571.

108. Notes on Native Affairs. The Question of "Time., in: The North-China Herald, 9/7/1906 (2039), p. 571.

109. United States Department of State 1909, p. 349.

110, 故宮博物院明淸檔案部 Gugong Bowuyuan Mingqing Dang'an Bu 1979, p. 385 (Guangxu $32 / 7 / 14)$.

111. Notes on Native Affairs. Not Easily Moved., in: The North-China Herald, 9/28/1906 (2042), p. 788. 
A primeira comissão deveria deliberar sobre o processo de reformas e elaborar um quadro normativo, tomando como modelo os melhores exemplos de outros países. Foi formada por 14 membros representando a maioria dos órgãos do governo central. Além disso, os governadores de quase todas as províncias foram convidados a mandarem representantes à capital para participar dos debates. Os resultados do trabalho dessa comissão deveriam ser apresentados à segunda comissão para uma revisão final. Essa comissão foi menor, sendo ela composta por três membros: Yikuang (príncipe Qing), Sun Jianai e Qu Hongji.

Segundo o plano dado pelo decreto de $1^{\circ}$ de setembro de 1906, a primeira parte das reformas deveria tratar da estrutura administrativa do império. Porém, propostas concretas sofreram considerável oposição de vários setores da administração, que temia perder influência por causa da reforma. Isso levou as comissóes a restringirem a primeira rodada das reformas ao governo central e adiar a reforma dos governos provinciais. Apesar das dificuldades, a comissão conseguiu chegar a uma reforma depois de dois meses de debates, e o decreto oficializando a reforma foi publicado a 6 de novembro de 1906. ${ }^{112}$

Depois da reforma do governo central, o segundo passo das reformas do estado tinha como objetivo os governos provinciais. Porém, após a reforma do governo central, foi notado um longo período de inatividade por parte do governo, que durou por toda a primeira parte de 1907. Essa falta de decretos foi recebida com impaciência pelo público e levou a especulações que os reacionários dentro da Corte poderiam ter ganho. Assim, já em janeiro de 1907, o jornal North China Herald, publicado em Xangai, considerava ter sido a reforma dos governos provinciais definitivamente colocada ad acta. ${ }^{113}$ Em fevereiro de 1907, o jornal considerava a China ter recaido na reação e exortava as potências extrangeiras a reconsiderar as suas atitudes perante a China, que, no ano passado (1906), haviam melhorado a ponto de «tratar a China como a um dos seus»., ${ }^{114}$

As atividades de reforma continuaram a partir do verão de 1907. Em uma nota ao Trono de 17 de julho de 1907, Yuan Shikai, vice-rei de Zhili, escreveuः «Nos últimos anos, não há um único país no mundo que não houvesse proclamado uma constituição.» Yuan Shikai pedia pesquisas mais profundas das constituições alemã e japonesa, uma vez que a situação desses dois países seria próxima à chinesa. ${ }^{115} \mathrm{E}$ de fato, mais tarde em 1907 , o governo enviou três comissários ao Japão, à Alemanha e ao Reino Unido.

A reforma dos governos provinciais foi promulgada a 7 de julho de $1907^{116}$, seguida pela eleição do primeiro conselho municipal da China em Tientsin, a 24 de julho de 1907. Ao mesmo tempo, surgiram discussões sobre uma possível reorganização mais profunda do governo central. Desde junho de 1907, houve propostas para formar um sistema de governo de

112. 故宮博物院明淸檔案部 Gugong Bowuyuan Mingqing Dangan Bu 1979, pp. 471-472 (Guangxu $32 / 9 / 20)$.

113. The Situation in China, in: The North-China Herald, 1/25/1907 (2059), p. 161.

114. Found Waiting, in: The North-China Herald, 2/1/1907 (2060), pp. 213-14.

115. 光緒政要Guangxu zhengyao, 卷 Cap. 33, p. 2156.

116. 故宮博物院明淸檔案部 Gugong Bowuyuan Mingqing Dang'an Bu 1979, pp. 510-511. (Guangxu $33 / 5 / 27)$. 
gabinete117, enviadas ao Trono em 28 de julho de 1907. Porém, também houve considerável oposição à introdução iediata de um sistema de governo de gabinete. ${ }^{118}$

Essa diferença de opinióes impossibilitou a criação de um gabinete. Mesmo assim, seguiram certas reformas da administração central que não só constituiram uma continuação das reformas de novembro de 1906, mas também tiveram importância para o próprio processo constituinte. Um dos órgãos designados para fazer parte do gabinete era uma autoridade responsável pela codificação de leis. As comissões de reformas criadas a 2 de setembro de 1906 não eram órgãos institucionalizados. E enquanto a Órgão para Investigação da Política (Kaocha Zhengzhi Guan) era mais uma autoridade transitória à qual competia colecionar e avaliar informações, ela ainda não estava equipada para cumprir a tarefa de realmente realizar a decisão de outorgar uma constituição.

Em outro documento apresentado ao Trono de 3 de agosto de 1907, Yuan Shikai queixou-se de que esse órgão não estava cumprindo as suas tarefas. ${ }^{119}$ Poucos dias depois, príncipe Yikuang e outros apresentaram uma petição conjunta ao Trono ${ }^{120}$, na qual sugeriram elevar a Autoridade para Investigação da Política (Kaocha Zhengzhi Guan) a Órgão de Codificação para o Governo Constitucional (Xianzheng Biancha Guan) e subordiná-la ao Conselho Imperial (Junjichu). A 13 de agosto de 1907, num decreto ${ }^{121}$ respondendo diretamente à proposta de Yikuang e de seus colegas, o Trono aprovou a proposta de criar a Órgão de Codificação para o Governo Constitucional (Xianzheng Biancha Guan) e ordenou que essa fosse subordinada ao Conselho Imperial (Junjichu) temporariamente, isso é, até que o Conselho de Ajuda Política (Zizhengyuan), o parlamento incipiente, fosse criado.

Esse decreto era mais um passo para gruadualmente tornar a administração central mais eficiente. Porém, mas que uma mera mudança de nomes e reorganização ${ }^{122}$, o estabelecimento da Órgão de Codificação para o Governo Constitucional (Xianzheng Biancha Guan) foi um marco institucional que levou a uma nova fase no processe constituinte da dinastia Qing ${ }^{123}$ e ao mesmo tempo demonstrava que a Corte de Pequim realmente dava importância ao objetivo de preparação constitucional. ${ }^{124}$ Como explicavam o príncipe Yikuang et. al. na nota introdutória à proposta de lei orgânica para o órgão, apresentada ao Trono a 24 de agosto de $1907^{125}$, o modelo era o órgão de pesquisa japonês criado no início da era Meiji.

117. Notes on Native Affairs. A proposed amalgamation, in: The North-China Herald, 6/21/1907 (2080), pp. 711-712; The Capital. The Proposed Cabinet, in: The North-China Herald, 9/6/1907 (2091), p. 556.

118.Ver, p. ex., a nota do censor Zhao Binglin ao Trono de 13 de agosto de 1907. 故 宮博物院明淸檔案

部 Gugong Bowuyuan Mingqing Dang'an Bu 1979, p. 511 (Guangxu 33/7/3).

119. Cit. in United States Department of State 1910, p. 191.

120. 故宮博物院明淸檔案部 Gugong Bowuyuan Mingqing Dang'an Bu 1979, p. 45 (Guangxu 33/7/5).

121. 故宮博物院明清檔案部 Gugong Bowuyuan Mingqing Dangan Bu 1979, pp. 45-46 (Guangxu $33 / 7 / 5)$.

122. Meienberger 1980, p. 57.

123. 趙林鳳, Zhao Linfeng 2014, p. 140.

124. 下修全 Bian Xiuquan 2006, p. 33.

125. 故宮博物院明清檔案部 Gugong Bowuyuan Mingqing Dangan Bu 1979, pp. 47-48. 
As atribuições do órgão iam muito além da mera compilação de um texto constitucional para a China. De acordo com a sua lei orgânica126, era dividido em dois departamentos: um departamento responsável por codificar leis e outro responsável por estatísticas. A responsabilidade pelas estatísticas parece estranha, mas derivava da tarefa de coletar dados estatísticos sobre outros países. $\mathrm{O}$ departamento de codificação era subdividido em três divisões: a) uma divisão era responsável pela constituição, b.) uma era responsável pelos códigos legais, c) a terceira era responsável por leis avulsas e regulamentos administrativos. Ademais, a Órgão de Codificação para o Governo Constitucional (Xianzheng Biancha Guan) tinha três escritórios: um escritório de questóes gerais, um escritório que funcionava como biblioteca e um escritório para traduções, cuja tarefa era traduzir escritos estrangeiros, especialmente as constituições de outros países.

Logo depois dos debates sobre a introdução de um gabinete, a atenção voltou-se para a criação de um parlamento. Um decreto de 20 de setembro de 1907127 estabeleceu o Conselho de Ajuda Política (Zizhengyuan), que seria a base para o vindouro parlamento. Um segundo decreto de 19 de outubro de 1907128 ordenou que fossem estabelecidas assembléias provinciais (Ziyiju). Quando do estabelecimento do proto-parlamento, seus membros acordaram reunir-se seis vezes por mês129, porém até março de 1908, eles não obtiveram importantes resultados.130 Só em meados de 1908, a 8 de julho de 1908, duas partes do regulamento interno do Conselho de Ajuda Política (Zizhengyuan) foram aprovadas por decreto imperial.131 De acordo com esse regulamento, o Conselho de Ajuda Política (Zizhengyuan) era uma assembléia unicameral, que porém já continha em si a semente de um futuro parlamento bicameral: Parte de seus membros era nomeada pelo governo central e outra parte pelas assembléias provinciais (Ziyiju). A assembléia teria uma sessão principal de três meses uma vez por ano, bem como um número não definido de sessões no entretempo.

Após duas semanas, a 22 de julho de 1908, a Corte de Pequim passou outro decreto ${ }^{132, \text { que }}$ não só aprovou as leis orgânicas das assembléias provinciais (Ziyiju), mas também ordenou que a a Órgão de Codificação para o Governo Constitucional (Xianzheng Biancha Guan) e o Conselho de Ajuda Política (Zizhengyuan) «rapidamente» preparassem um esboço de uma constituição monarquica baseada nas melhores regras dos diversos países. Os dois órgãos também foram encarregados de conjuntamente prepararem esboços para uma lei eleitoral e uma lista de problemas a serem resolvidos nos anos antes da criação do parlamento. $\mathrm{E}$ realmente, os dois órgãos rapidamente prepararam os esboços: Foram aprovados por decreto imperial apenas um mês depois, a 27 de agosto de $1908 .{ }^{133}$

126. 故宮博物院明淸檔案部 Gugong Bowuyuan Mingqing Dang'an Bu 1979, pp. 49-51.

127. 故宮博物院明清檔案部 Gugong Bowuyuan Mingqing Dang'an Bu 1979, p. 606.

128. 故宮博物院明清檔案部 Gugong Bowuyuan Mingqing Dang'an Bu 1979, p. 667.

129. Notes on Native Affairs. The Imperial Assembly, in: The North-China Herald, 11/1/1907 (2099), p. 287.

130. Notes on Native Affairs. The Tzechenyuen, in: The North-China Herald, 3/6/1908 (2117), p. 555.

131. 故宮博物院明淸檔案部 Gugong Bowuyuan Mingqing Dangan Bu 1979, pp. 627-629.

132. 故宮博物院明淸檔案部 Gugong Bowuyuan Mingqing Dangan Bu 1979, pp. 683-684.

133.故宮博物院明淸檔案部 Gugong Bowuyuan Mingqing Dang'an Bu 1979, pp. 54-67; 67-68. 
O Esboço Constitucional por Outorgação Imperial (Qinding Xianfa Dagang) foi o primeiro documento constitucional da China. Tratava-se de um curto esboço baseado na constituição japonesa de 1890 (especialmente em seu primeiro capítulo sobre a posição do Imperador), mas que claramente ainda não estava completo. Tinha vinte 23 artigos, dos quais os primeiros 14 definiam os «direitos do Imperador» e os nove restantes os «direitos e deveres do povo». Com o seu foco nos poderes do Imperador, foi criticado por ser até mais conservador que seu modelo japonês. ${ }^{134}$

Ao mesmo tempo, o decreto de 27 de agosto de 1908 anunciou um plano detalhando os passos a serem tomados nos nove anos seguintes a fim de preparar a China para a introdução completa da constituição. Segundo o plano, a constituição definitiva teria entrado em vigor em 1916.

Porém, o projeto constitucional da Corte fracassou. O governo realizou uma parte dos pontos previstos no plano de nove anos, mas a dinastia não conseguiu manter a lealdade dos atores relevantes na sociedade chinesa. O esboço de 1908 foi fortemente criticado por ser demasiado conservador e exaltar os poderes do Imperador, e a partir de 1909, o estabelecimento das assembléias provinciais mudou o cenário político, aumentando fortemente a pressão externa sobre a Corte de Pequim.135 Em meio a revoltas, o governo foi obrigado a outorgar outro esboço de constituição em novembro de 1911, seguindo o modelo britânico. Porém, apenas poucas semanas depois, a dinastia Qing foi forçada a abdicar. Foi proclamada, a $1^{\circ}$ de janeiro de 1912, a República da China, acabando com a tentativa de reformar o Império por dentro.

\section{IV+ Conclusões}

Durante as décadas seguintes à proclamação da República da China, a reação do governo chinês ao movimento constitucional era normalmente descrevida como insincera e, na verdade, como uma tentativa reacionária de adiar a verdadeira introdução do constitucionalismo na China. ${ }^{136}$ Os esforços de reforma política na primeira decada do século XX eram muitas vezes interpretados como um passo para trás, como um tentativa de recentralizar o poder nas mãos da aristocracia de Pequim. ${ }^{137}$ Mas, como pesquisas mais recentes mostram ${ }^{138}$, o governo estava de fato trabalhando em sua própria versão de constitucionalismo, em uma tentativa de «reforma dentro da tradição» ${ }^{139}$. Embora interpretasse o conceito de constitucionalismo de seu próprio modo conservador, estava de fato tentando executar reformas, açóes essas que foram em parte freadas por conflitos entre diversos setores do governo.

Porém, além disso, há um outro aspecto do incipiente constitucionalismo que não recebou bastante consideração dos historiadores jurídicos. A China tem uma tradição milenar de

134. 下修全 Bian Xiuquan 2006, p. 45.

135. Meienberger 1980, p 13.

136. Li 1968, pp. 208-209.

137. Seitz 2000, p. 106.

138. P. ex. Meienberger 1980, p. 13.

139. Meienberger 1980, p. 13. 
sofisticadas estruturas políticas, para as quais usar o termo «constituição» no seu sentido de «quadro normativo de uma estrutura política» é perfeitamente válido.140 O quê era, então, a função da nova constituição na China imperial?

O constitucionalismo acarretava um «enorme» programa de reformas políticas, mas ao mesmo tempo não era só a introdução de um sistema «representativo» 141 , até mesmo porque o parlamento a ser introduzido não teria o poder que tinham outros parlamentos da época. A codificação de uma constituição servia também para legitimar o governo interna e externamente. A experiência do Japão, que conseguiu, em poucas décadas, tornar-se uma potência imperialista, foi decisiva para as reformas chinesas. As missóes ao exterior, os institutos de pesquisa e o próprio processo de reformas políticas seguiam o modelo japonês. Como o hino e a bandeira nacional, que não por acaso foram escolhidos mais ou menos na mesma época, a carta constitucional, que estava para ser proclamada no final do processo, seria uma espécie de símbolo do Estado. Os líderes políticos da China percebiam a codificação de uma constituição como uma tendência global, na qual a China tinha que participar para tornar-se um membro da ordem mundial que se encontrava em formação.

\section{Bibliografia}

Found Waiting, in: The North-China Herald, 2/1/1907 (2060), pp. 213-14.

Li, Chien-Nung - The Political History of China, 1840-1928. Translated and Edited by Ssu-Yu Teng and Jeremy Ingalls. Fifth printing.: D. van Nostrand. Princeton, N.J 1968

Mayer, Otto - Deutsches Verwaltungsrecht, Vol. 1, 3. ed., Duncker \& Humblot, München und Leipzig 1924

Meienberger, Norbert. The emergence of constitutional government in China (1905-1908). The concept sanctioned by the Empress Dowager Tz' $u$-hsi. P. Lang (Schweizer Asiatische Studien/ Etudes Asiatiques Suisses vol. 1), Bern 1980.

Nish, Ian (Ed.) - Annual Reports on China, 1906-1913. University Publications of America: An Imprint of CIS (British Documents on Foreign Affairs: Reports and Papers from the Foreign Office Confidential Print, Part I: From the Mid-Nineteenth century to the First World War, Series E: Asia, 1860-1940, Volume 14), Lanham 1993

Notes on Native Affairs. The Question of a Constitution, in: The North-China Herald, 8/31/1906 (2038), p. 544

140. Zhao Hui 2012, p. 38.

141. Essa foi a sucinta definição de «constitucional» dada reiteradamente pelo representante dos EUA à China na época, William Rockhill. United States Department of State 1910, pp. 179, 191. 
Notes on Native Affairs. The Question of "Time., in: The North-China Herald, 9/7/1906 (2039), p. 571

Notes on Native Affairs. Not Easily Moved, in: The North-China Herald, 9/28/1906 (2042), p. 788.

Notes on Native Affairs. A proposed amalgamation, in: The North-China Herald, 6/21/1907 (2080), pp. 711-12.

Notes on Native Affairs. The Imperial Assembly, in: The North-China Herald, 11/1/1907 (2099), p. 287.

Notes on Native Affairs. The Tzechenyuen, in: The North-China Herald, 3/6/1908 (2117), p. 555.

Röhl, Wilhelm (Ed.) - History of Law in Japan since 1868, Brill (Handbuch der Orientalistik 5/12), Leiden 2005

Pusey, James Reeve. China and Charles Darwin. Council on East Asian Studies, Harvard University; Distributed by Harvard University Press (100), Cambridge, Mass. 1983.

Seitz, Konrad - China. Eine Weltmacht kehrt zurück. 1. Aufl. Siedler, Berlin 2000.

The Capital. The Proposed Cabinet, in: The North-China Herald, 9/6/1907 (2091), p. 556.

The Situation in China, in: The North-China Herald, 1/25/1907 (2059), p. 161.

United States Department of State (Ed.) - Papers relating to the foreign relations of the United States with the annual message of the president transmitted to Congress December 3, 1906. In two parts. Part one. 2 volumes, Government Printing Office, Washington 1909

United States Department of State (Ed.) - Papers relating to the foreign relations of the United States with the annual message of the president transmitted to Congress December 3, 1907. In two parts. Part one. 2 volumes. Government Printing Office, Washington 1910

Zhao Hui - Rethinking Constitutionalism in Late 19th and Early 20th Century China. Harvard, Cambridge (Massachusetts) 2012.

下修全 Bian Xiuquan - 近代中国史法文本的囚史解冈. Jindai Zhongguo xianfa wenben de lishi jiedu. 第 1 版 1a edição. 知 囚冈权出版社 Zhishi chanquan chubanshe, 北京 Pequim 2006

光緒政要Guangxu Zhengyao (近代中國史料叢刊/沈雲龍主編 1,345: 第三十五輯 Jindai Zhongguo shiliao congkan/Shen Yunlong (ed.), No 1345: di 35 ji), 5 volumes, 文海出版 社 Wenhai chubanshe, 台北 Taipé 民國58 [1969] 
故宮博物院明清檔案部 Gugong Bowuyuan Mingqing Dangan Bu (Ed.) - 清末籌備立 憲檔案史料 Qingmo choubei lixian dang'an shiliao, 2 volumes, 中華書局 Zhonghua Shuju, 北京 Pequim 1979.

家永三郎 Ienaga Saburô; 松永昌三 Matsunaga Shouzou; 江村栄一 Emura Eiichi - 明治 前期の憲法構想 Meiji zenki no kenpô kôsô, 初版 1a edição, 福村出版 Ed. Fukumura, 東 京 Tóquio 1967

大石眞 Ôishi Makoto - 日本憲法史 Nihon kenpôshi, 初版第2刷 1a ed., 2a impr., 有斐閣 Yuuhikaku, 東京 Tóquio 1996

趙林鳳 Zhao Linfeng - 汪榮寶. 中國近代憲法第一人. Wang Rongbao. Zhongguo jindai xianfa di yi ren. 初版 1a edição. 新銳文創 (秀威資訊) Xinrui Wenchuang (Xiuwei zixun) (血歷史 Xue Lishi, 54), 臺北 Taipé 2014. 
Recebido em: 28/01/2016

Aceito em: 01/03/2016

\section{Como citar}

BANDEIRA, Egas Moniz. O advento do constitucionalismo na China.

Ballot. Rio de Janeiro: UERJ. Volume 2 Número 1 Janeiro/Abril 2016.

pp. 81-94. Disponível em: [http://www.e-publicacoes.uerj.br/index.php/ ballot]

\section{cc) (i) (2) \\ (c) $\mathrm{BY}$ NA}

A Revista Ballot está licenciada sob uma licença Creative Commons Atribuição - Não Comercial - Compartilha Igual 3.0 Não Adaptada. 